\title{
Analisis Performa Jalan Dengan Menggunakan Metode Pada Kawasan Pecinan - Pati Sebagai Pengaruh Restrukturisasi Pasar Rogowangsan
}

\author{
lin Irawati \\ Jurusan Teknik Sipil Universitas Semarang \\ email : iin.irawati5477@gmail.com
}

\begin{abstract}
Transportation is the lifeblood of providing distribution service activities in supporting community activities, both within the city and in the wider region. If there is no balance between structuring land use with the existing transportation system, it will cause an urban problem, one of which is traffic congestion. One factor in traffic congestion is the renovation or restructuring of traditional markets into modern markets. One study of the area affected by the restructuring of the traditional market (Rogowangsan market) became a modern market is the Chinatown in the city of Pati. The method used to analyze the performance of the road is the IHCM method, with a performance indicator in the form of Level of Service (LOS). From the resulting analysis obtained DS value $=0.67$ and performance is at LOS C.
\end{abstract}

Keyword : Performance, Level of Service, Degree of Saturation

\begin{abstract}
Abstrak
Transportasi merupakan urat nadi dalam memberikan kegiatan pelayanan jasa distribusi dalam menunjang usaha-usaha kegiatan masyarakat, baik di dalam kota maupun di wilayah yang lebih luas. Apabila tidak ada keseimbangan antara penataan tata guna lahan dengan sistem transportasi yang ada, maka akan menimbulkan suatu permasalahan perkotaan, salah satunya adalah kemacetan lalulintas. Salah satu faktor kemacetan lalulintas adalah adanya renovasi atau restrukturisasi pasar tradisional menjadi pasar modern. Salah satu kajian wilayah yang terkena dampak dari restrukturisasi pasar tradisional (pasar Rogowangsan) menjadi pasar modern adalah wilayah Pecinan di kota Pati. Metode yang digunakan untuk menganalisis performa ruas jalan adalah dengan metode MKJI 1997, dengan indikator performa berupa Level of Service (LOS). Dari analisis yang dihasilkan diperoleh nilai DS $=0.67$ dan performa berada pada LOS C.
\end{abstract}

Kata Kunci : Kinerja, tingkat pelayanan jalan, derajat kejenuhan

\section{PENDAHULUAN}

Cahyono, (2014), menyebutkan bahwa sistem transportasi dan pengembangan lahan (land development) saling kait mengkait dan di dalam sistem transportasi tujuan dari perencanaan adalah menyediakan fasilitas untuk pergerakan penumpang dan barang dari satu tempat ke tempat yang lain atau dari berbagai pemanfaatan lahan, sedangkan dari sisi perencanaan pengembangan lahan, tujuan dari perencanaan adalah untuk tercapainya fungsi bangunan dan harus menguntungkan. Berdasarkan hal tersebut, maka diperlukan keseimbangan antara penataan kota dengan sistem transportasi. Dampak yang ditimbulkan karena ketidakseimbangan tersebut adalah kemacetan lalulintas.

Salah satu faktor yang menyebabkan kemacetan lalulintas adalah adanya restrukturisasi pasar tradisional menjadi pasar modern. Salah satunya adalah pasar yang ada di kota Pati, yaitu pasar Rogowangsan. Alokasi pedagang ke kawasan tersebut, dengan adanya pemanfaatan trotoar serta sisi badan jalan oleh pedagang, mempengaruhi performa atau kinerja pada ruas jalan. Tidak optimalnya pelayanan jalan, disebabkan oleh penggunaan trotoar dan sisi badan jalan yang memunculkan hambatan samping (side friction), seperti parkir liar dari kendaraan serta pejalan kaki pada sisi badan jalan. 


\section{TUJUAN PENELITIAN}

Tujuan penelitian yang dilakukan adalah adalah :

1. Mengetahui nilai V/C yang ada pada ruas jalan di kawasan Pecinan,sebagai akibat dari pengaruh restrukturisasi pasar Rogowangsan Pati.

2. Mengetahui LOS dari ruas jalan di kawasan Pecinan - Pati yang menjadi dampak oleh kegiatan restrukturisasi pasar Rogowangsan.

\section{METODE PENELITIAN}

Metodologi dari penelitian yang dilakukan dapat dilihat pada gambar 1 berikut ini.

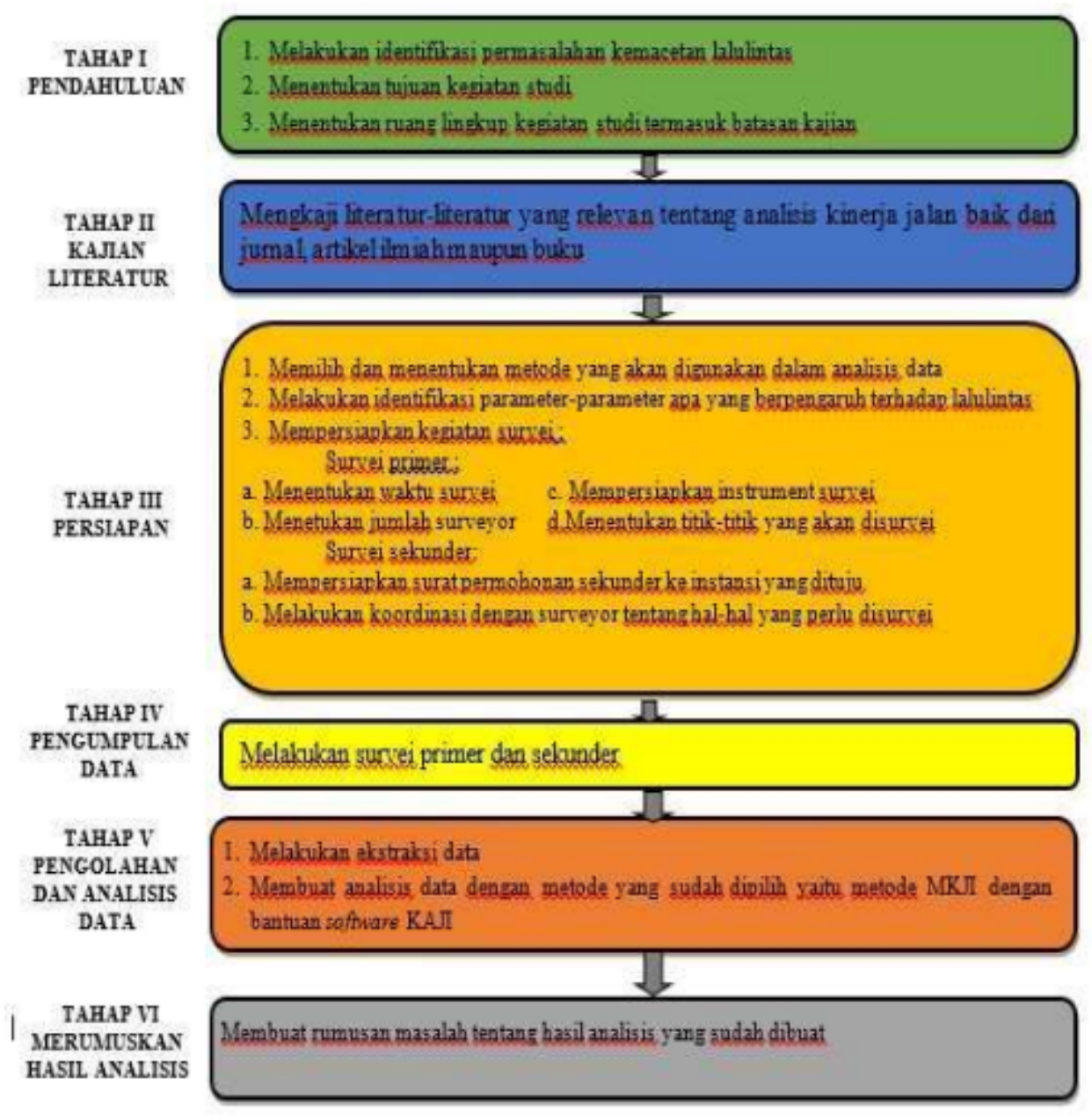

Sumber : Hasil Pentahapan Peneliti, 2017

Gambar 1. Metodologi Penelitian

\section{METODE PENGUMPULAN DATA}

Dalam penelitian ini, ada dua cara pengumpulan data untuk keperluan analisis, yaitu dengan melakukan survei primer dan survei sekunder. Survei primer merupakan pengumpulan data yang diperoleh langsung di lapangan. Survei primer dilakukan selama 3 hari, yaitu hari 
Senin (mewakili hari kerja), Sabtu dan Minggu, jam 05.30 - 07.30. Data primer yang dibutuhkan untuk kajian studi ini adalah sebagai berikut :

1.Volume kendaraan, yang meliputi data :

a) Volume kendaraan per jam.

b) Classified volumes ( kelas kendaraan berdasarkan dimensinya ).

c) Survei hambatan samping.

- Geometrik jalan.

- Tata guna lahan ( land use ).

- Volume pejalan kaki.

- Kelengkapan jalan,seperti rambu, marka, fasilitas pejalan kaki, lampu penerangan.

Data sekunder yang dibutuhkan dalam kajian studi ini meliputi data jumlah penduduk kota Pati. Data kependudukan tersebut selanjutnya digunakan untuk penentuan nilai faktor penyesuaian kapasitas terhadap ukuran kota.

\section{METODE ANALISIS DATA}

Metode analisis yang digunakan dalam penelitian ini adalah metode MKJI. Pemilihan metode MKJI digunakan untuk mengetahui indikator kinerja jalan yang berupa V/C dalam penentuan tingkat pelayanan atau Level of Service ( LOS ).

\section{ANALISIS ARUS LALULINTAS}

Dari data volume kendaraan yang sudah disurvei, maka arus lalulintas dapat dilihat pada tabel 1 di bawah ini.

Tabel 1. Arus Lalulintas

\begin{tabular}{c|c|c|c}
\hline $\begin{array}{c}\text { Jenis } \\
\text { Kendaraan }\end{array}$ & $\begin{array}{c}\text { Jumlah } \\
\text { Kendaraan }\end{array}$ & EMP & $\begin{array}{c}\text { Arus Lalulintas }(\mathrm{V}=\mathrm{Q} \mathrm{x} \\
\text { EMP) } \\
\text { (smp/jam) }\end{array}$ \\
\hline MC & 3099 & 0.25 & 774.75 \\
\hline LV & 401 & 1 & 401 \\
\hline HV & 0 & 1.2 & 0 \\
\hline UMC & 0 & 0 & 0 \\
\hline
\end{tabular}

Sumber : Hasil Hitungan Penelti, 2017

\section{ANALISIS KAPASITAS JALAN}

Rumus untuk kapasitas jalan adalah sebagai berikut : 


\section{$C=$ Co $\times$ FCW $\times$ FCSP $\times$ FCFC $\times$ FCCS}

Co $=$ kapasitas dasar, yang diperoleh berdasarkan tipe jalan. Tipe jalan pada penelitian ini adalah 2/2 UD, sehingga nilai Co $=2900 \mathrm{smp} / \mathrm{jam}$ (MKJI 1997, halaman $5-50$, tabel C -1 : 1, Jalan Perkotaan)

$\mathrm{FCW}$ = faktor penyesuaian kapasitas terhadap lebar lajur. Lebar geometrik pada lajur lalulintas lokasi penelitian adalah 3 meter, sehingga nilai FCW $=0.87$ (MKJI 1997, halaman 5 - 51, tabel C -2 : 1, Jalan Perkotaan)

FCSP $=$ faktor penyesuaian kapasitas terhadap pemisahan arah. Pemisahan arah pada segmen jalan dalam penelitian ini adalah $50-50$, sehingga nilai FCSP $=1$ (MKJI 1997, halaman $5-52$, tabel C $-3: 1$, Jalan Perkotaan)

FCFC = faktor penyesuaian kapasitas terhadap hambatan samping. Berdasarkan data yang diperoleh di lapangan, kelas hambatan samping yang ada sepanjang jalan adalah sangat tinggi. Hal tersebut terlihat dari : 1. penggunaan sisi badan jalan sebagai tempat parkir sepeda motor dan mobil (terjadi pengurangan lebar jalan 1.75 meter per sisi jalan, total per jalur $=3.5$ meter untuk pengurangan geometrik jalan), 2. penggunaan sisi badan jalan untuk PKL (di lapangan terjadi pengurangan sebesar $1-2$ meter), 3. banyaknya frekwensi pejalan kaki per jam yang melebihi 50 pejalan kaki, sehingga nilai FCSF $=0.73$ (MKJI 1997, halaman $5-53$, tabel $\mathrm{C}-4: 1$, Jalan Perkotaan yang tidak memiliki bahu jalan)

FCCS = faktor penyesuaian kapasitas terhadap ukuran kota. Ukuran kota didasarkan pada jumlah penduduk kota Pati, sehingga nilai FCCS $=0.94$ (MKJI 1997, halaman $5-2654$, tabel C -5 : 1, Jalan Perkotaan)

Dari uraian tersebut di atas, maka nilai kapasitas (C), dapat dihitung sebagai berikut :

$C=2900 \times 0.87 \times 1 \times 0.73 \times 0.94=1731.28 \mathrm{smp} / \mathrm{jam}$

\section{ANALISIS DERAJAT KEJENUHAN (DS) DAN LEVEL OF SERVICE (LOS)}

Setelah diperoleh nilai arus (V) dan kapasitas (C), maka dilakukan analisis perbandingan arus dan kapasitas (V/C) yang merupakan nilai derajat kejenuhan. Nilai V/C tersebut akan digunakan sebagai penentu level of service (LOS) dalam menilai performa (kinerja) ruas jalan. Analisis V/C adalah sebagai berikut :

$\mathrm{V} / \mathrm{C}($ derajat kejenuhan $)=1175.75 / 1731.28=0.67$

Dari nilai $\mathrm{V} / \mathrm{C}=0.67$, maka dapat ditentukan kinerja jalan berada pada LOS C. Kinerja ruas jalan pada LOS C menunjukkan bahwa kebebasan bermanuver di dalam aliran lalulintas semakin terbatas dan perpindahan lajur membutuhkan kewaspadaan pengemudi.

\section{KESIMPULAN}

Berdasarkan hasil analisis yang dilakukan, maka dapat diambil kesimpulan berdasarkan rumusan masalah. Kesimpulan tersebut adalah bahwa nilai V/C yang ada pada ruas jalan di kawasan Pecinan,sebagai akibat dari pengaruh restrukturisasi pasar Rogowangsan Pati adalah sebesar 0.67 dan performa jalan berada pada LOS C. 


\section{DAFTAR PUSTAKA}

Cahyono, T., ( 2014 ), Analisis Dampak Lalulintas, 2014

Departemen Pekerjaan Umum. (1997). Manual Kapasitas Jalan Indonesia (MKJI), Direktorat Jenderal BinaMarga, Jakarta.

Gea, M.S.A., \& Harianto, J., (2013), Analisis Kinerja Ruas Jalan Akibat Parkir Pada Badan Jalan (Studi Kasus: Pasar dan Pertokoan di Jalan Besar Delitua), Jurnal Dipublikasikan, Universitas Sumatera Utara.

Ofyar, Z., T., (1997), Perencanaan dan Pemodelan Transportasi.

Syahrizal, R, M., Rauf, S., Pasra, M., (2012), Pemetaan Perkembangan Tata Guna Lahan pada Jalan Tol Kota Makasar, Jurnal Penelitian Jurusan Teknik Sipil Fakultas Teknik Universitas Hasannuddin Makasar. 